\title{
Filho da dor, pai do prazer: o samba entre a morte e a vida
}

Luca Argel

Instituto de Literatura Comparada Margarida Losa

Resumo: Um sobrevoo pelo processo de invenção do Brasil como empreendimento colonial, observando as idiossincrasias da sua formação enquanto estado, e da emergência de uma consciência nacional - observando, aliás, a não-coincidência entre estes dois fatores, que corresponde a um antagonismo entre o Brasil institucional e a "brasilidade" como sentimento coletivo. Neste sentido, daremos destaque às respostas subversivas oferecidas pela cultura popular, nomeadamente o aparecimento do samba, no início do século XX.

Palavras-chave: Brasil, samba, colonialismo, cultura popular

Abstract: A flight over the process of invention of Brazil as a colonial enterprise, observing the idiosyncrasies of its formation as a state, and the emergence of a national conscience - noting, in fact, the non-coincidence between these two factors, which corresponds to an antagonism between Brazil institutional and "Brazilianness" as a collective feeling. In this sense, we will highlight the subversive responses offered by popular culture, namely the appearance of samba, in the beginning of the 2oth century.

Keywords: Brazil, samba, colonialism, popular culture 
“O Brasil não é para principiantes”. Esta é uma frase muito ouvida em análises de conjuntura política no Brasil, ou em comentários sobre notícias recentes. Mesmo para nós, brasileiros, é sempre uma tarefa difícil explicar o nosso país. Eu próprio, quanto mais conheço a nossa história, mais me dou conta de como ela está repleta de contradições. De como, em momentos decisivos, o Brasil não obedece ao que seria o curso natural de um jovem país, surgido no cenário internacional após um longo passado de colonização europeia - assim como todos os outros países do continente americano.

É verdade que existe um marco fundante comum, entre todos os países americanos, que é o genocídio dos povos nativos do continente. A narrativa histórica hegemônica raramente assume o ponto de vista desses povos, mas, para quem já vivia na América na altura da chegada dos colonizadores, o fim do mundo aconteceu ali mesmo, no século XVI. No que nós chamamos século XVI. E foi só com o fim do mundo para os povos nativos americanos que se tornou possível a fundação de um novo mundo, do qual o Brasil vai fazer parte. Do qual todos nós somos parte, até hoje.

Como toda colônia, o que nós chamamos hoje de Brasil não nasce, de todo, como um país. O Brasil nasce apenas como um território a ser espoliado. Durante a maior parte da sua história ele foi visto e tratado como um empreendimento - um empreendimento, com a licença do anacronismo, não-sustentável. A atitude puramente extrativista diante dos recursos naturais locais, somada com uma limitação objetiva de contingente populacional na metrópole, determinou que a ocupação do território brasileiro, durante séculos, acontecesse somente ao longo de uma faixa litorânea estreita, em cidades não planeadas para se viver, mas apenas para se escoar as commodities extraídas em direção ao mercado europeu. E essa relação transitória e descartável com o lugar é uma das nossas principais idiossincrasias. Nenhum dos personagens que fundaram este novo mundo via o Brasil como um lar. Nem a administração colonial, nem os investidores estrangeiros, e nem os trabalhadores, fossem eles livres ou escravizados, tinham a intenção de criar raízes. O Brasil era um sítio onde se ia para trabalhar, e voltar de preferência o mais rápido possível, com o máximo de lucro possível. Por isso o gentílico do Brasil, “brasileiro”, termina em “eiro”. Um sufixo que na língua portuguesa designa não a naturalidade de uma pessoa mas o seu ofício. Os "brasileiros" eram os que comercializavam a nossa primeira commodity de sucesso, a madeira do pau-brasil, e não quem nascia no território. Estes, seguindo a lógica gramatical, deveriam chamar-se "brasilianos”. Mas aí está a questão: não existiam “brasilianos”. Não existiam porque ninguém se considera originário de um empreendimento. Dizer-se "brasiliano" durante quase todo o período colonial devia ser algo equivalente a dizer-se, hoje, que se é “MacDonaldês” ou “Uberiano” ou “Teslaense”. Não faz sentido.

O desinteresse em tornar o Brasil um empreendimento minimamente habitável começou a mudar depois de um evento muito estranho, desses que só o Brasil teve, e que desafia toda a lógica historiográfica: a transferência da capital do reino, junto com toda a sua corte, da metrópole para a colônia, em I808. E, poucos anos depois, o 
Brasil seria palco de uma outra contradição histórica, ainda maior: a nossa independência é declarada pelo príncipe herdeiro do trono português, em I822. Isso é fantástico. Ao contrário de todos os nossos vizinhos, a independência do Brasil não aconteceu para derrubar a monarquia, mas para mantê-la. Não só para manter a monarquia, mas para manter a escravatura também. Mas sobre isso falaremos mais adiante. Continuando o fio de contradições históricas, podemos também pensar na nossa proclamação da República, levada a cabo em 1889 por um marechal monarquista. Ou ainda na nossa ditadura militar mais recente, iniciada em 1964, e que, ao contrário das dos nossos vizinhos sul-americanos, caiu sem ser derrotada, sem data certa, e mesmo assim só depois de se auto-amnistiar dos seus próprios crimes. 0 Brasil não é mesmo para principiantes.

Não temos espaço para discutir aqui os meandros de cada um destes episódios, nem é este o meu objetivo. 0 que quero extrair destas aparentes contradições é que, embora cada uma delas represente uma espécie de ruptura, de mudança de regime, muito mais forte é o sentido de continuidade que elas permitem dar àquilo que o Brasil sempre foi, e continua sendo: um empreendimento colonial, extrativista, e não-sustentável. Basta observar a organização social do Brasil atual para comprovar: nossa matriz econômica continua sendo a exportação de commodities, extraídas do território às custas da degradação ambiental e do extermínio dos povos nativos; os cargos administrativos e o capital continuam concentradíssimos nas mãos de herdeiros brancos; e, consequentemente, a força de trabalho continua a ser obtida através da domesticação e exploração de corpos negros e pardos.

É nesta última parte que eu gostaria de me deter. A experiência da escravatura no Brasil talvez seja o nosso traço sócio-cultural mais significativo. Se assumirmos um outro ponto de vista que a historiografia hegemônica também raramente assume, o ponto de vista dos 12 milhões de africanos sequestrados e trazidos ao continente americano como escravizados, veremos que, para essas pessoas poderem participar na construção daquele novo mundo que surgia, elas também tiveram que experimentar o fim do seu próprio mundo. A experiência da diáspora dilacera identidades; desagrega famílias e comunidades; extingue hábitos, idiomas, culturas. Por isso, toda cultura de diáspora (seja ela africana, cigana, muçulmana, judia, ou qualquer outra) vai tentar, no seu ponto de chegada, reconstruir tudo aquilo que foi destruído na deslocação. No caso do Brasil, a diáspora africana criou um complexo cultural riquíssimo, que, não sendo mais propriamente africano, é hoje considerado um símbolo da identidade nacional brasileira. Do que podemos chamar de "brasilidade".

O grande problema é que esse complexo cultural da diáspora africana sempre foi essencialmente incompatível com a lógica do Brasil enquanto empreendimento colonial. 0 que é perfeitamente compreensível, uma vez que a cultura da diáspora nasceu justamente como resistência à lógica colonial escravista. E é aqui que começa o conflito entre o que Luiz Antonio Simas define como o "Brasil contra a brasilidade": 
- Se o Brasil-empreendimento-colonial necessita do trabalho para gerar riqueza; para os criadores da "brasilidade", marcados pela experiência da escravidão, trabalho é sinônimo de sofrimento. "Trabalhar, trabalhar! Trabalhar pra quê? Se eu trabalhar eu vou morrer”. Esses são versos de um canto de louvação a Seu Zé Pelintra, entidade de uma religião nascida no seio da diáspora africana no Brasil, a Umbanda. Ou então: "Trabalho igual ao meu todo mundo quer, mas nem todos podem encontrar. Entro às onze horas, saio ao meio dia, e tenho uma hora pra almoçar”. Esse é um refrão do compositor Ismael Silva, cuja obra é considerada o marco inicial do samba, gênero musical também nascido no seio da diáspora africana;

- Se o Brasil-empreendimento-colonial exige a disciplina e a obediência dos corpos para o trabalho; a brasilidade responde com a ginga e flexibilidade dos movimentos da capoeira e dos passos do samba, onde reina o improviso e a invenção;

- Se o Brasil empreendimento-colonial precisa de previsibilidade, austeridade e ordem na sua linha de produção; a brasilidade responde com a beleza caótica do carnaval.

Este antagonismo entre o empreendimento colonial e a cultura da diáspora, onde o primeiro está constantemente ocupado na dominação e sujeição do segundo, tem como sustentação e combustível o racismo estrutural. A ideia de supremacia branca vigorou durante toda a escravatura, e na prática continuou vigorando mesmo depois da abolição. É por isso que todas as manifestações do complexo cultural diaspórico no Brasil foram, em algum momento, perseguidas pelo Estado Brasileiro. A capoeira foi proibida, o samba foi proibido, as religiões de matriz africana foram proibidas. A descriminalização delas foi acontecendo ao longo do século XX, impulsionada por um novo momento histórico que o planeta todo vivia. Era o momento de estabelecimento de uma nova ordem mundial, pós-Segunda Guerra Mundial, em que o Estado Brasileiro se viu na posição de apresentar-se ao mundo como um país com uma identidade nacional própria. Isto é, com uma identidade cultural, para além da visão do empreendedorismo colonial, e também para além das tentativas de imitação de uma almejada identidade europeia, da qual o grande paradigma foi o desejo que havia no início do século de transformar, por exemplo, o Rio de Janeiro numa Paris tropical.

É verdade que já desde aquela época o nosso movimento artístico modernista enfrentava esse mesmo problema identitário. E, diante dos trabalhos formidáveis de pesquisa e sistematização da cultura brasileira que a geração modernista fez, se há uma constatação inequívoca a que eles chegaram é a de que o eixo central da identidade brasileira passa, fundamentalmente, pela diáspora africana. Então não demorou muito até que o Departamento de Propaganda do Estado Brasileiro reconhecesse que o nosso complexo cultural diaspórico, até então criminalizado - e onde vamos encontrar precisamente o samba, a capoeira, os festejos de rua como o carnaval (mas não só), as religiões como a umbanda e o candomblé, e etc. -,afinal poderia ser bom cartão de visita do Brasil para o mundo. Contudo, depois de 350 anos de escravatura, 
o racismo entranhado na sociedade e nas estruturas de poder exigia que todas estas manifestações culturais, para serem estimuladas e exportadas com apoio do estado, passassem antes por um processo de “desafricanização". Ou, com outras palavras: de branqueamento. Por isso, por exemplo, a artista que serviu como grande "embaixadora cultural" do Brasil no exterior, na época, era uma mulher branca: Carmem Miranda. Por isso os maiores cantores de rádio da época, que popularizaram o samba para todo o país, Francisco Alves e Mário Reis, eram brancos. Por isso as primeiras gravações de samba não continham os instrumentos mais associados à africanidade: os tambores. Havia um grande empenho em se desassociar a identidade brasileira "oficial" da negritude, a despeito dos nossos produtos culturais mais bem sucedidos virem justamente de invenções da negritude. Mais uma para nossa coleção de contradições.

O mais curioso dessa história é que um dos elementos mais projetados da cultura da diáspora negra no Brasil, o samba, diante de todas as tentativas de apagamento, de controlo e de apropriação, adotou uma estratégia de sobrevivência muito original. Ao invés de se sectarizar, de se entrincheirar nos seus redutos para se auto-preservar, ele de certa forma se deixou apropriar, em troca de uma trégua na perseguição. 0 samba, num gesto muito perspicaz de diplomacia, aproveita a oportunidade de ser alçado à posição de gênero nacional para se legitimar e desfazer os estigmas que existiam sobre ele, e com isso poder existir livremente, sem a criminalização de que tinha sido vítima no passado. Aí, com os caminhos desimpedidos, ele se populariza imensamente. Para que isso acontecesse, é claro que houve concessões por parte dos sambistas. Uma delas foi, por exemplo, que os sambistas deixassem de exaltar a malandragem e a aversão ao trabalho, e passassem a adotar um discurso mais patriótico, disciplinado e moralizador. E isso aconteceu, de facto. Os sambistas mudaram o discurso.

Mas em contrapartida, o samba tinha na manga uma estratégia de manutenção da sua essência que escapou ao Estado, e que reside na seguinte constatação: não são só as letras de samba que passam mensagens. Uma escola de samba, quando desfila, por exemplo, vem com seus cantores, mas vem também acompanhada de uma orquestra de percussões: a bateria. E os ritmos tocados pelos instrumentos de uma bateria de escola de samba também contam histórias e passam mensagens, para quem as sabe descodificar. É o que Luiz Antonio Simas chama de "gramática do tambor". Explicando brevemente: a bateria de cada escola de samba é consagrada a um orixá, e cada orixá tem o seu toque, que corresponde a uma história própria. Ou seja, por mais que a letra de um samba no desfile de carnaval exalte grandes figuras da nação, fale de presidentes, marechais e imperadores, há outras histórias sendo contadas paralelamente, pelos toques dos instrumentos, para os iniciados que conhecem a gramática do tambor. E é neste aproveitamento de frestas, de pontos cegos do sistema, que o samba foi ao longo do tempo sobrevivendo à perseguição num mundo hostil, conquistando mais espaço para existir com dignidade, e ao mesmo tempo conseguindo conservar minimamente a sua essência de cultura diaspórica. 
Agora penso em nossa posição no mundo. Não na dos brasileiros, nem na de qualquer outro grupo social em particular, mas em nossa posição enquanto espécie, num mundo que todo dia parece se aproximar mais rapidamente do fim - seja pela degradação do ambiente, seja pela degradação do próprio tecido social. Será possível salvar este mundo? Ou ainda: será desejável salvá-lo? O mundo moderno, fundado no século XVI sobre os pilares do genocídio dos nativos americanos, da escravização dos africanos, e que, por mais transformações que sofra, tem se mostrado incapaz de abdicar das suas estruturas coloniais de exploração, ele deve ser salvo?

O antropólogo Eduardo Viveiros de Castro tem afirmado já há algum tempo que, se quisermos pensar o fim do mundo, mais vale ouvir o que têm a dizer os sujeitos que já passaram por um. Nesta matéria somos nós os principiantes. Como sobreviveram os nativos americanos e os africanos ao fim dos seus mundos? Não podendo salvá-los por inteiro, as suas culturas de diáspora conseguiram de alguma forma preservar uma parte deles. A minha experiência pessoal no estudo e na prática de uma manifestação cultural diaspórica como o samba me ensinou muito sobre o valor, por exemplo, dos laços comunitários. Percebi que toda a forma de se fazer e de se vivenciar o samba está a serviço do convívio das pessoas. Desde o formato de se tocar em roda, da partilha do mesmo espaço comum entre intérpretes e público, dos refrões simples que chamam todos a participar, da presença indispensável de comida e bebida, tudo é pensado com o intuito de aproximar as pessoas, de reforçar o sentido de coesão do grupo - o que, se pararmos para analisar, é algo fundamental para a sobrevivência num contexto de diáspora. Entre tudo aquilo que se perdeu no fim do mundo daqueles sujeitos, este tanto se salvou. E do nosso mundo, o que escolheremos salvar?

\section{Notas}

* Luca Argel (Rio de Janeiro, 1988), é graduado em música pela UNIRIO e mestre em literatura pela Universidade do Porto. Vive desde 2012 em Portugal, onde trabalha como cantor e compositor. Tem livros de poesia publicados no Brasil, em Espanha e em Portugal, e quatro álbuns lançados, o último dos quais, Samba de Guerrilha é resultado de uma pesquisa continuada sobre a história política do samba.

' Este ensaio foi escrito no âmbito da investigação desenvolvida no Instituto de Literatura Comparada, Unidade I\&D financiada por Fundos Nacionais através da FCT - Fundação para a Ciência e para Tecnologia (UIDB/00500/2020). 


\section{Bibliografia}

Lopes, Nei (1981), O Samba na Realidade: a utopia da ascensão social do sambista, Rio de Janeiro, Codecri.

-- / Luiz Antonio Simas (2015), Dicionário da História Social do Samba, Rio de Janeiro, Civilização Brasileira.

Simas, Luiz Antonio (2013), Pedrinhas Miudinhas, Rio de Janeiro, Mórula.

-- (2018), Almanaque Brasilidades: um inventário do Brasil popular, Rio de Janeiro, Bazar do Tempo.

-- (2019), O Corpo Encantado das Ruas, Rio de Janeiro, Civilização Brasileira.

-- (2021), Umbandas: uma história do Brasil, Rio de Janeiro, Civilização Brasileira.

Viveiros de Castro, Eduardo (2014), "A escravidão venceu no Brasil. Nunca foi abolida - entrevista a Alexandra Lucas Coelho", Público, <www.publico.pt/2014/03/16/ mundo/entrevista/a-escravidao-venceu-no-brasil-nunca-foi-abolida-162815I> (último acesso em 21/12/2021). 